\title{
Economic evaluation of prolonged and enhanced ECG Holter monitoring in acute ischemic stroke patients
}

Citation for published version (APA):

Diekmann, S., Hoerster, L., Evers, S., Hiligsmann, M., Gelbrich, G., Groeschel, K., Wachter, R., Hamann, G. F., Kermer, P., Liman, J., Weber-Krueger, M., Wasem, J., Neumann, A., \& Find-AF RANDOMISED Investigators and Coordinators (2019). Economic evaluation of prolonged and enhanced ECG Holter monitoring in acute ischemic stroke patients. Current Medical Research and Opinion, 35(11), 1859-1866. https://doi.org/10.1080/03007995.2019.1646000

Document status and date:

Published: 02/11/2019

DOI:

10.1080/03007995.2019.1646000

Document Version:

Publisher's PDF, also known as Version of record

Document license:

Taverne

Please check the document version of this publication:

- A submitted manuscript is the version of the article upon submission and before peer-review. There can be important differences between the submitted version and the official published version of record.

People interested in the research are advised to contact the author for the final version of the publication, or visit the DOI to the publisher's website.

- The final author version and the galley proof are versions of the publication after peer review.

- The final published version features the final layout of the paper including the volume, issue and page numbers.

Link to publication

\footnotetext{
General rights Owners
rights.

- You may freely distribute the URL identifying the publication in the public portal. please follow below link for the End User Agreement:

www.umlib.nl/taverne-license

Take down policy

If you believe that this document breaches copyright please contact us at:

repository@maastrichtuniversity.nl

providing details and we will investigate your claim.
}

Copyright and moral rights for the publications made accessible in the public portal are retained by the authors and/or other copyright owners and it is a condition of accessing publications that users recognise and abide by the legal requirements associated with these

- Users may download and print one copy of any publication from the public portal for the purpose of private study or research.

- You may not further distribute the material or use it for any profit-making activity or commercial gain

If the publication is distributed under the terms of Article $25 \mathrm{fa}$ of the Dutch Copyright Act, indicated by the "Taverne" license above, 


\title{
Economic evaluation of prolonged and enhanced ECG Holter monitoring in acute ischemic stroke patients
}

\author{
Sandra Diekmann ${ }^{\mathrm{a}}$, Laura Hörster ${ }^{\mathrm{a}}$, Silvia Evers ${ }^{\mathrm{b}, \mathrm{c}} \mathbb{D}_{\mathrm{D}}$, Mickaël Hiligsmann $^{\mathrm{b}}$ (D), Götz Gelbrich ${ }^{\mathrm{d}, \mathrm{e}}$, Klaus Gröschelf, \\ Rolf Wachter ${ }^{g, h}$, Gerhard F. Hamann ${ }^{i}$, Pawel Kermer', Jan Liman', Mark Weber-Krüger ${ }^{\mathrm{g}}$, for the

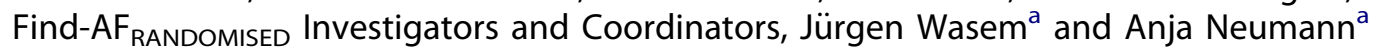 \\ ${ }^{a}$ Institute for Health Care Management and Research, University of Duisburg-Essen, Essen, Germany; ${ }^{b}$ Faculty of Health, Medicine and Life \\ Sciences, Department of Health Services Research, CAPHRI Care and Public Health Research Institute, Maastricht University, Maastricht, The \\ Netherlands; 'Centre of Economic Evaluations, Trimbos Institute, Netherlands Institute of Mental Health and Addiction, Utrecht, The

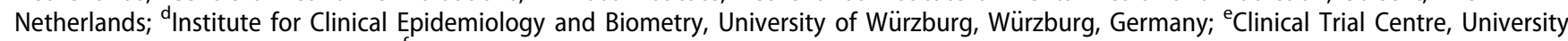 \\ of Würzburg, Würzburg, Germany; 'Department of Neurology, University Medical Centre of Johannes Gutenberg University Mainz, Mainz,

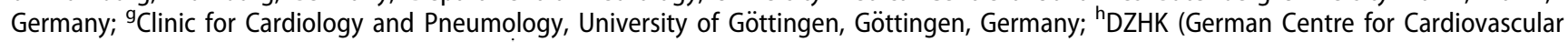 \\ Research), partner site Göttingen, Germany; 'Clinic for Neurology and Neurological Rehabilitation, Bezirkskrankenhaus Günzburg, Günzburg, \\ Germany; ${ }^{j}$ Clinic for Neurology, Hospital Nordwest-Krankenhaus Sanderbusch, Sande, Germany; ${ }^{\text {} C l i n i c ~ f o r ~ N e u r o l o g y, ~ U n i v e r s i t y ~ o f ~}$ \\ Göttingen, Göttingen, Germany
}

\begin{abstract}
Objective: Atrial fibrillation (AF) is a major cause for recurrent stroke, has severe impact on a patient's health and imposes a high economic burden for society. Current guidelines recommend $24 \mathrm{~h}$ ECG monitoring (standard-of-care, $\mathrm{SoC}$ ) to detect AF after stroke to reduce the risk of future events. However, paroxysmal AF (PAF) is difficult to detect within this period as it occurs infrequently and

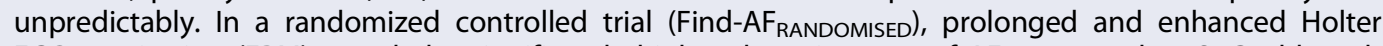
ECG monitoring (EPM) revealed a significantly higher detection rate of AF compared to SoC, although its cost-effectiveness has not yet been investigated.

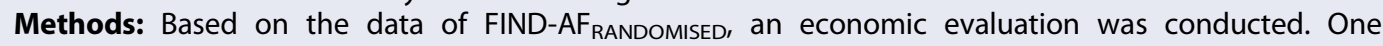
group received EPM for 10 days after the event, and at 3 and 6 months; the other group received SoC. Healthcare resource use and quality of life (QoL) data were measured at baseline, and after 6 and 12 months. Incremental costs and quality-adjusted life years (QALYs) between both groups were compared. Non-parametric bootstrapping and one-way-sensitivity analyses were performed.

Results: A total of 281 patients with healthcare resource use and QoL data for all measurement points were considered in the economic evaluation (complete case analysis, CCA). The CCA yielded nonsignificant $315 €$ lower mean costs and 0.0013 less QALYs for patients receiving EPM with no statistically significant differences in any cost categories. Sensitivity analyses revealed robust results. Bootstrapping the results indicated moderate probability of cost-effectiveness.

Conclusions: EPM yielded reduced not significantly different costs without affecting QoL and may be a useful strategy to detect PAF in acute ischemic stroke patients in time.
\end{abstract}

\section{ARTICLE HISTORY}

Received 19 March 2019

Revised 21 June 2019

Accepted 17 July 2019

\section{KEYWORDS}

Atrial fibrillation; secondary prevention; cost-benefit analysis; quality-adjusted life years; stroke

\section{Introduction}

Stroke represents a high economic burden for society. Annually, EU countries spend on average $27 €$ billion on stroke related costs $^{1}$, meaning that around $3-4 \%$ of health expenditures (on average for eight European countries) are spent on costs caused by the acute event and later due to rehabilitation and care $^{2}$. Discounted life time costs of stroke were $43,129 €$ per case in Germany and are expected to rise in the future considering the ageing population ${ }^{3}$.

Atrial fibrillation (AF) is one major cause of stroke, often leading to more severe symptoms and worse outcomes than stroke of other etiologies ${ }^{4,5}$. Moreover, the risk of AF patients suffering from recurrent stroke is five times that of patients not suffering from $A F^{6}$. Prognoses expect the number of people affected by AF to double by $2050^{4}$.

Detection of AF differs depending on the form of AF. German and international guidelines recommend a minimum of 24 hours of continuous electrocardiogram (ECG) monitoring (stroke unit monitoring and/or Holter ECG) to detect $A F$ in stroke patients ${ }^{7,8}$. Permanent or persistent $A F$ is uncomplicated to detect within this period ${ }^{9}$, whereas it is difficult to detect paroxysmal AF (PAF) due to its unpredictable and infrequent occurrence ${ }^{10}$. Hence, the updated guideline of the European Society of Cardiology from 2016 recommends short-term ECG followed by ECG for at least 72 hours for ischemic stroke patients ${ }^{11}$. 
After detection of $\mathrm{AF}$, current guidelines recommend initiation of oral anticoagulant $(O A C)^{12,13}$. Timely initiated, OAC therapy in AF patients reduces the risk of ischemic stroke by $60-70 \%$ compared to placebo ${ }^{14}$, leads to a similar survival rate compared to patients without AF history ${ }^{15}$, decreases mortality rate by $25 \%{ }^{11,14}$ and, consequently, may positively affect follow-up costs associated with stroke.

In terms of cost-effectiveness, 30 day handheld intermittent ECG screening for the detection of silent $A F$, an asymptomatic form of $\mathrm{AF}$, proved to be dominant compared to $24 \mathrm{~h}$ ECG screening in 75/76year old patients with a recent ischemic stroke ${ }^{16}$. Mass screening with two weeks of intermittent ECG for asymptomatic AF (75/76 year old) resulted in $4313 €$ per quality adjusted life year (QALY) $)^{17}$. In the German setting, 7 day Holter monitoring for the detection of PAF in patients with acute cerebral ischemia was cost-effective compared to $24 \mathrm{~h}$ ECG when considering lifetime costs and QALYs ${ }^{18}$.

Find-AF RANDOMISED (Clinical Trial Registration - URL: http:// www.clinicaltrials.gov; unique identifier: NCT01855035) is an open-label randomized and controlled prospective multicenter trial comparing repeated enhanced and prolonged Holter ECG monitoring (EPM) to continuous $24 \mathrm{~h}$ ECG monitoring (standard of care, SoC) for detection of PAF in acute ischemic stroke patients in the German setting ${ }^{5}$. The primary endpoint "newly detected atrial fibrillation ( $\geq 30$ seconds) after 6 months or before recurrence of cerebral or systemic thromboembolism" resulted in significantly higher AF detection rates in the intervention group (EPM: 13.5\%; SoC: $4.5 \%)^{19}$. However, the detection of AF might lead to expensive OAC therapy. Economic evaluations play an increasing role in healthcare decision making alongside clinical outcomes. To our knowledge, the cost-effectiveness of EPM compared to SoC for the detection of PAF has not yet been

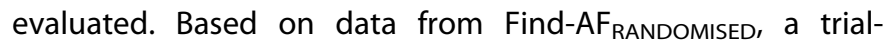
based economic evaluation will be performed. More specifically, costs of the initial stroke will be compared to the health-related quality of life (HRQoL) for one year of follow-up ${ }^{5}$.

\section{Methods}

\section{Study design}

A cost-utility analysis was conducted based on the data from the trial Find-AF $\mathrm{FANDOMISED}_{\text {using healthcare resource }}$ use and the secondary endpoint HRQoL. The economic evaluation was performed according to national and international guidelines to reduce methodological and reporting uncertainties $^{20-22}$. The latest issues of the Declaration of Helsinki, the International Conference on Harmonisation of Technical Requirements for Registration of Pharmaceuticals for Human Use (ICH) guidelines for good Clinical Practice and Committee for Proprietary Medicinal Products (CPMP)/ $\mathrm{ICH} / 135 / 95$ (as far as applicable) and national laws apply to the persons involved in this study.

\section{Setting, intervention and comparator}

Patients were included prospectively in four stroke units (SUs) which were different in size and catchment areas across Germany. The following inclusion criteria applied: recent cerebral ischemia defined as stroke (sudden focal neurologic deficit lasting $>24 \mathrm{~h}$ consistent with the territory of a major cerebral artery and categorized as ischemic) and/ or a corresponding lesion on brain imaging, stroke symptoms starting $\leq 7 \mathrm{~d}$ ago, 60 years or older and modified Rankin Scale $\leq 2$ (prior to index event) ${ }^{5}$. EPM was performed on patients in the intervention group for 10 days after the initial stroke, and after 3 and 6 months $s^{5}$. Patients in the control group received continuous ECG monitoring once, directly after the initial stroke for a minimum of 24 hours (SoC). The randomization was conducted by a 1:1 ratio to either EPM or SoC $\mathrm{C}^{5}$.

\section{Data collection}

Healthcare resource use and quality of life (QoL) data for the economic evaluation were gathered at baseline, and after 180 and 360 days for the past 6 months from the measurement point 5 .

Patients with available data for all three measurement points were considered in the complete case analysis (CCA). In a second analysis, all patients with complete data for at least two measurement points were included for analysis to avoid sampling bias. Missing data were imputed by mean costs and mean utilities for the respective time period and group.

Both samples were compared to each other and to the initial sample regarding age, sex and the baseline score of the National Institutes of Health Stroke Scale (NIHSS), which quantifies the severity of stroke.

\section{Valuation of utilities and costs}

HRQoL and healthcare resource use were measured at baseline, 180 and 360 days respectively for the past 6 months from the measurement point. QoL of the patients was measured with the generic, standardized and valid EQ-5D-3L measurement tool ${ }^{23,24}$. The EQ-5D-3L reflects the self-reported health and is organized into five dimensions (mobility, self-care, daily activities, pain/discomfort, anxiety/ depression) which can be rated with "no", "some" or "major" problems resulting in an individual health state ${ }^{25}$. Its use in stroke patients is already established ${ }^{26}$. Utility values were attached to each health state based on a utility index determined with the time-trade-off method in a German population ${ }^{27}$.

The evaluation of the stroke-related healthcare resource use throughout the trial was performed from the societal perspective with a self-designed 9-item resource use measurement instrument.

Unit costs, unit of measures and sources of valuation of costs are described in Table 1. Medical devices were calculated per prescription ${ }^{28}$ and costs for medication were 
Table 1. Valuation of costs per cost category.

\begin{tabular}{|c|c|c|c|}
\hline & Unit cost $(€)$ & $\begin{array}{l}\text { Unit of } \\
\text { measure }\end{array}$ & Source \\
\hline General practitioner & 20.94 & \multirow[t]{8}{*}{ Visits } & 28 \\
\hline Neurologist & 46.69 & & 28 \\
\hline Cardiologist/gastroenterologist/internist & 68.32 & & 28 \\
\hline Visceral surgeon & 45.30 & & 28 \\
\hline Physical therapy & 17.14 & & 28 \\
\hline Occupational therapy & 39.16 & & 28 \\
\hline Speech therapy & 40.29 & & 28 \\
\hline Intervention costs ${ }^{\mathrm{a}}$ & 44.63 & & 28 \\
\hline Hospital visits & 619.18 & \multirow[t]{4}{*}{ Days } & 28 \\
\hline Rehabilitation (inpatient) & 48.74 & & 28 \\
\hline Rehabilitation (outpatient) & 127.22 & & 28 \\
\hline Productivity loss & 84.84 & & 31 \\
\hline
\end{tabular}

${ }^{a}$ Mean costs: general practitioner and cardiologist contact.

considered with the daily defined dosage (DDD) $)^{29}$. Costs of formal care were based on information of the Federal Ministry of Health ${ }^{30}$. The friction cost approach (FCA) was used to calculate productivity losses (temporary and permanent disability ${ }^{20,31}$. The FCA supposes that costs for society arise during the friction period (until the replacement of the worker or the return to work) - assumed with 90 days $^{32}$ and only $80 \%$ of the losses are considered. In contrast, the human capital approach (HCA) calculates the productivity losses until death ${ }^{33,34}$.

Since the follow-up period was one year, discounting was not necessary. Missing frequencies or periods were replaced by the modus and respective mean per group for each measurement point. To account for potential differences in baseline utilities or healthcare resource use between the intervention and control groups, adjustment by regression analysis was performed ${ }^{24,35}$. In general, uncertainty was addressed with conservative estimates.

\section{Data analysis}

Non-parametric Mann-Whitney tests (continuous variables) or chi-squared tests (categorical variables) were performed on non-normally distributed variables. Statistical tests were two-sided and $p$ values $<.05$ were considered as statistically significant.

Mean values, standard deviations (SDs), 95\% confidence intervals (Cls) or percentages were used to describe the data. Non-parametric bootstrapping (5000 resamples) was applied to estimate sampling uncertainties in mean values ${ }^{22,33}$. The cost-effectiveness acceptability curve (CEAC) is based on various incremental cost effectiveness ratios (ICERs). An ICER is the difference in costs between EPM and SoC divided by their differences in QALYs and represents the additional cost per QALY gained of EPM compared to SoC ${ }^{36}$.

In Germany, no thresholds for the willingness-to-pay (WTP) exist; cost-effectiveness acceptability curves (CEAC) were used as probability measures to provide information about the likelihood of the intervention being a cost-effective alternative for a certain threshold ${ }^{22}$.

Robustness and reliability of results were assessed by sensitivity analyses: first, productivity losses were calculated by using the $\mathrm{HCA}^{20}$; second, only healthcare related costs were considered (e.g. as third-party payers need this information to consider reimbursement); and third, regression analysis was performed to adjust for differences in baseline utilities ${ }^{24}$.

For all statistical analyses SPSS (version 22) was used and, if applicable, Excel 2007.

\section{Results}

\section{Descriptive analysis - complete case analysis}

A total of 398 eligible patients were randomized; 200 patients were randomized to EPM and 198 to SoC; 281 (71\%) patients had data for all three measurement points and were included in the CCA. A total of 117 patients (29\%) had data for less than three measurement points due to death, not being personally reachable or being unwilling to participate in the cost-effectiveness analysis. The mean age of patients included in the CCA was 72 years (range $60-91$ ) and $64 \%$ of the patients were male; $50 \%$ of the patients showed minor stroke symptoms according to the NIHSS scale at baseline. The demographic characteristics were not distinctly different between the EPM and SoC groups, or between the initial and CCA samples.

Mean age, gender and the percentage with an NIHSS score higher than two can be found for the initial and CCA samples in Table 2. In the second analysis, 317 of 398 patients (80\%) had data for at least two measurements and were included for analysis. Their demographic characteristics were close to those of the initial sample $(n=398)$ (for details, see Online Resource 1).

\section{Resource use and costs}

At baseline, mean costs per patients in the SoC group were $494 €$ compared to $164 €$ per patient in the EPM group. After adjusting for differences in baseline costs, total adjusted mean societal costs were $4377 €$ per patient (median = $2438 €$ ) for the EPM group and $4692 €($ median $=3122 €$ ) for the SoC group (nonsignificant); $73 \%$ of costs occurred between baseline and 180 days. For this period, mean costs were $3160 €$ in the EPM group and $3423 €$ in the SoC group.

Table 3 presents mean costs, mean utilities and QALYs for one year of the CCA and the second analysis for all measurements (baseline, 180 days, 360 days). The second analysis showed similar results with no statistically significant differences in mean costs.

Mean utilities of patients in the EPM group revealed no statistically significant differences compared to those of the SoC groups for all measurements, either in the CCA or in the second analysis (see Table 3). In the CCA, the QALYs differed by 0.0013 between groups (second analysis: 0.0113 ) and were statistically not significantly different.

Overall, the EPM group indicated lower mean costs $(-315 €, p$ value $=.424)$ and slightly lower mean QALYs.

Table 4 displays all cost categories and presents bootstrapped mean costs with standard deviations, the percentage of patients who used the specific health services or caused non-healthcare costs and the difference in costs between the groups (with $95 \% \mathrm{Cl}$ ). In the one-year follow-up 
Table 2. Patient characteristics of the initial sample and the CCA sample.

\begin{tabular}{|c|c|c|c|c|c|c|c|c|}
\hline & Initial sample $(n=398)$ & EPM $(n=200)$ & SoC $(n=198)$ & $p$ value & CCA $(n=281)$ & $\mathrm{EPM}(n=142)$ & SoC $(n=139)$ & $p$ value \\
\hline \multicolumn{9}{|l|}{ Demographic characteristics } \\
\hline Female & $160(40 \%)$ & $85(42.5 \%)$ & 75 (37.9\%) & & $101(36 \%)$ & $56(39 \%)$ & 45 (33\%) & \\
\hline NIHSS $>2$ & $206(51.9 \%)$ & $110(55 \%)$ & 96 (48.7\%) & $.111^{\mathrm{b}}$ & $139(49.6 \%)$ & $74(52.1 \%)$ & 65 (47.1\%) & $.186^{\mathrm{b}}$ \\
\hline
\end{tabular}

Abbreviations. CCA, Complete case analysis; EPM, Prolonged and enhanced Holter ECG monitoring; NIHSS, National Institutes of Health Stroke Scale; SoC, Standard-of-care.

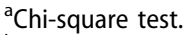

${ }^{\mathrm{b}}$ Mann-Whitney $U$ test.

'One patient in the SoC group did not have NIHSS baseline score.

Table 3. Mean values: cost and utility data for the CCA and the second analysis.

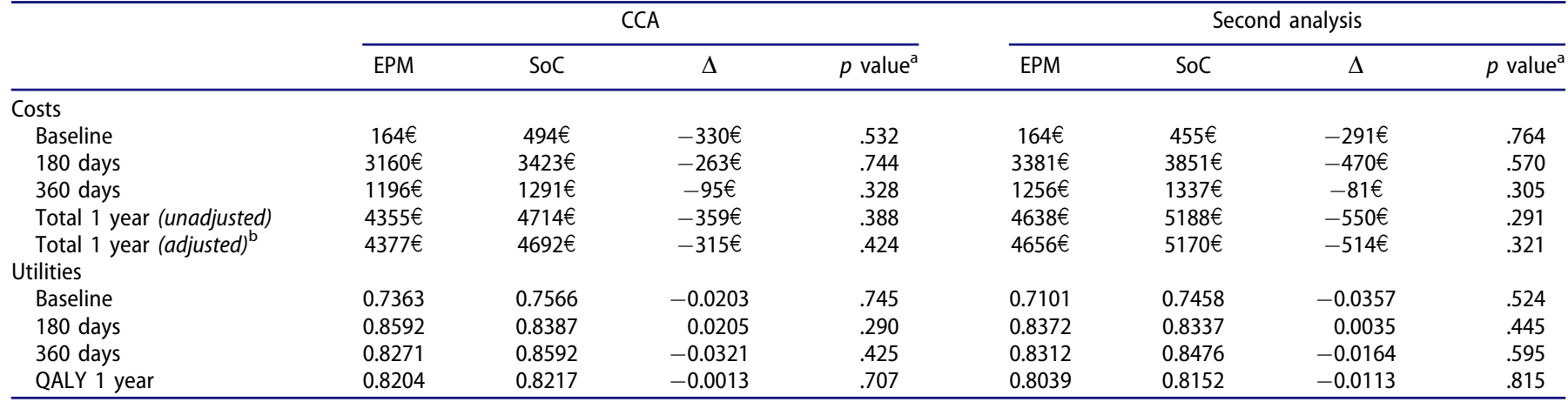

Abbreviations. CCA, Complete case analysis; EPM, Prolonged and enhanced Holter ECG monitoring; QALY, Quality adjusted life year; SoC, Standard-of-care.

${ }^{a}$ Mann-Whitney $U$ test.

${ }^{\mathrm{b}}$ Adjusted by regression analysis.

Table 4. Resource use and bootstrapped mean costs for one year of follow-up, CCA (unadjusted).

\begin{tabular}{|c|c|c|c|c|c|c|}
\hline & \multicolumn{2}{|c|}{ EPM $(n=142)$} & \multicolumn{2}{|c|}{ SoC $(n=139)$} & \multirow[t]{2}{*}{$p$ value $^{a}$} & \multirow[t]{2}{*}{$\Delta$ costs $(€)(95 \% \mathrm{Cl})$} \\
\hline & Use (\%) & Mean $(€) \pm S D$ & Use (\%) & Mean $(€) \pm S D$ & & \\
\hline Formal care & 13.4 & $425 \pm 95$ & 10.1 & $389 \pm 130$ & .391 & 36 ( -290 to 311$)$ \\
\hline Specialists & 42.3 & $59 \pm 9$ & 47.5 & $60 \pm 7$ & .356 & $-1(-22$ to 21$)$ \\
\hline Hospital visits & 4.2 & $194 \pm 127$ & 9.4 & $586 \pm 219$ & .082 & $-393(-329$ to 57$)$ \\
\hline Rehabilitation (overall) & 48.6 & $1682 \pm 181$ & 57.6 & $1905 \pm 185$ & .400 & $-223(-743$ to 280$)$ \\
\hline Inpatient rehabilitation & 44.4 & $1625 \pm 176$ & 51.8 & $1823 \pm 193$ & .525 & $-198(-697$ to 304$)$ \\
\hline Physical therapy & 34.5 & $220 \pm 37$ & 37.4 & $261 \pm 42$ & .506 & $-40(-146$ to 65$)$ \\
\hline Occupational therapy & 21.1 & $301 \pm 69$ & 20.9 & $315 \pm 68$ & .981 & $-14(-197$ to 182$)$ \\
\hline Speech therapy & 9.2 & $143 \pm 46$ & 12.9 & $193 \pm 51$ & .313 & $-50(-190$ to 82$)$ \\
\hline Medical devices & 25.4 & $257 \pm 55$ & 21.6 & $170 \pm 37$ & .387 & $87(-39$ to 226$)$ \\
\hline Medication & 99.3 & $474 \pm 38$ & 99.3 & $383 \pm 28$ & .394 & 91 (0 to 186$)$ \\
\hline Intervention costs & 100.0 & $133.89 \pm 0$ & - & 0 & $<.0001$ & 134 (134 to 134$)$ \\
\hline$\Sigma$ healthcare costs & & $4020 \pm 395$ & & $4384 \pm 414$ & .315 & $-365(-1452$ to 772$)$ \\
\hline
\end{tabular}

Abbreviations. Cl, Confidence interval; EPM, Enhanced and prolonged Holter ECG monitoring; SD, Standard deviation; SoC, Standard-of-care.

a Mann-Whitney $U$ test.

period, $90 \%$ of total costs were related to healthcare costs; only $10 \%$ were associated with productivity losses. Inpatient rehabilitation costs accounted for about $40 \%$ of total costs of the healthcare resource use (EPM: 38\%; SoC: 39\%). In the CCA, $44 \%$ of 200 patients in the EPM group and $50 \%$ of 198 patients in the SoC group received inpatient rehabilitation, which was performed in $97 \%$ and $95 \%$ of cases within the first 180 days after stroke for patients in the EPM and SoC groups, respectively. In this period, rehabilitation, hospitalization and cure were the most expensive cost categories.

\section{Cost-effectiveness and sensitivity analyses}

Figure 1 shows the cost-effectiveness (CE) of EPM compared to SoC over a range of theoretical CE thresholds for the CCA, the second analysis and two of the three sensitivity analyses (please see Online Resource 2 for the CEAC of the third sensitivity analysis). Considering a WTP of at least 25,000€ per QALY gained, in the CCA the proportion of bootstrapped iterations at or below this threshold is $60 \%$, indicating a probability of the EPM being cost-effective compared to SoC of around $60 \% ; 41 \%$ of the bootstrapped iterations indicate 

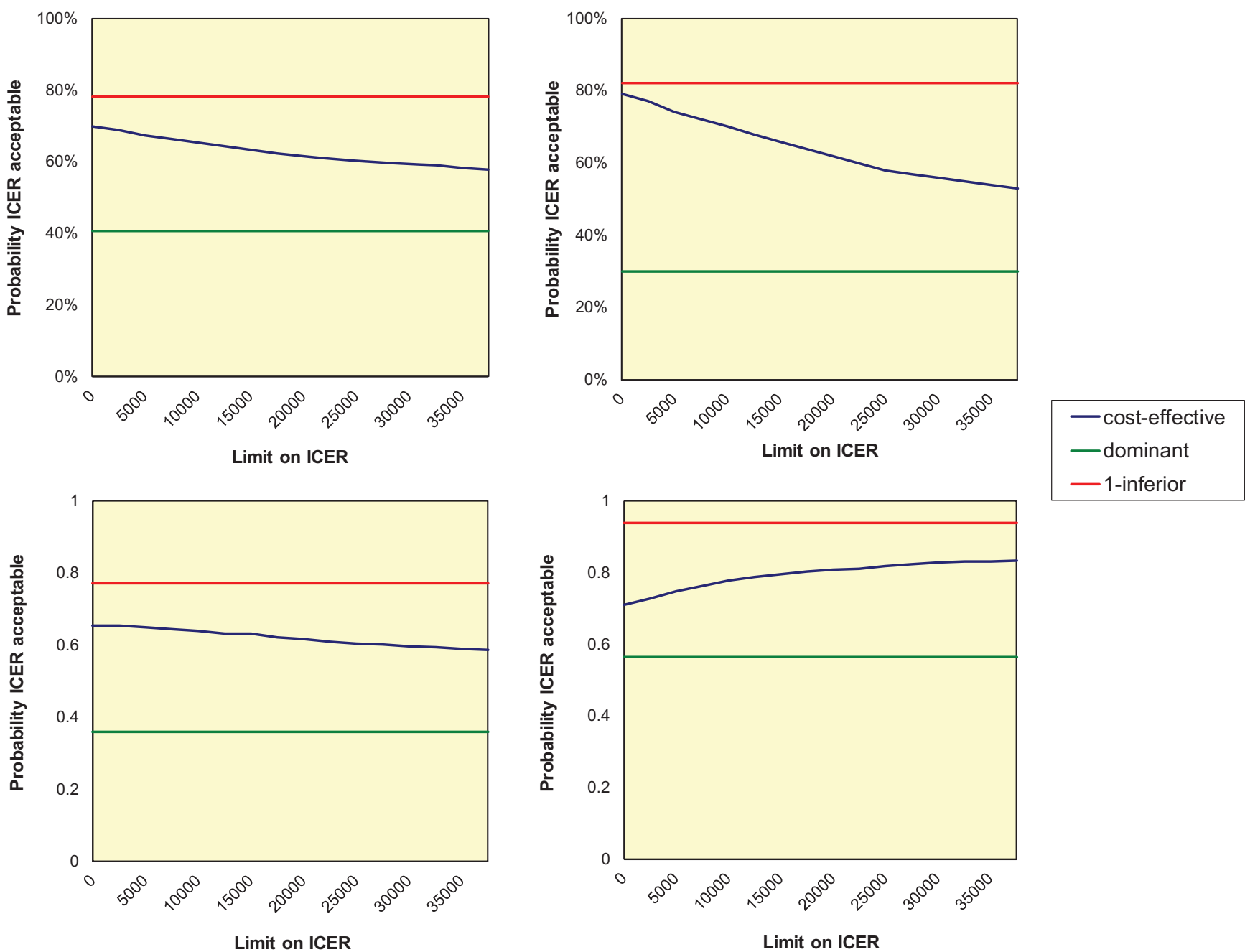

Figure 1. Depiction of cost effectiveness acceptability curves (CEACs) for the CCA, the second analysis and two sensitivity analyses (HCA and adjusted baseline utilities) (read from top left to bottom right). The CEACs describe the likelihood of EPM compared to SoC being cost-effective (blue line), dominant (green line) or inferior (red line). Abbreviation. ICER, Incremental cost-effectiveness ratio.

that EPM may be dominant (cost-saving and more effective) compared to SoC. The results of the second analysis and of two sensitivity analyses lead to similar outcomes (see Figure 1). Adjusting baseline utilities increases the probability to around $82 \%$ for a WTP of at least $25,000 €$ per QALY gained and to $56 \%$ of being dominant.

\section{Discussion}

\section{Main findings}

The healthcare resource use and HRQoL of ischemic stroke patients $>60$ years of age in Germany were evaluated for one year of follow-up. The main cost drivers were rehabilitation, cure, medication and formal care. Most of the costs occurred within the first 6 months after stroke.

In the CCA and the second analysis, no statistical differences between costs or in HRQoL occur within the follow-up period of one year. Mean costs and mean medication costs of the intervention group were not significantly higher, even though additional conservatively estimated intervention costs of $134 €$ applied and more patients in the EPM group received OAC therapy (EPM: $18 \%$; SoC: $13 \%)$.
The CEACs reveal uncertainty with regard to the costeffectiveness results but show a tendency towards a moderate probability of the EPM being more cost-effective within a one-year period compared to SoC. The robustness of results is supported by the bootstrapped incremental outcomes and conducted sensitivity analyses. Overall, changes in the application of methods were largely robust in results. Neither costs nor utilities revealed significant differences between the compared groups in any analysis.

FIND-AF RANDOMISED $_{\text {was }}$ powered to the primary endpoint "newly detected AF within 6 months" and proved that the detection rate of PAF in patients was significantly higher in the EPM group compared to the SoC group ${ }^{19}$. Hence, the underlying economic evaluation used the secondary end-

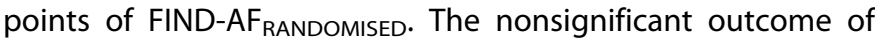
the $C E$ analysis may be interrelated with the lack of power in the economic evaluation part of FIND-AF RANDOMISED.

\section{Comparison with other studies}

Comparing the results with previous conducted studies is difficult due to different inclusion criteria, sample sizes, time horizons or models used. Based on a Markov model, 7 day 
Holter monitoring in patients with cerebral ischemia is costeffective compared to $24 \mathrm{~h}$ ECG when considering a lifetime horizon $^{18}$. In contrast, the present economic evaluation only considers the first year after the initial event, in which most costs related to the follow-up stroke care occur. It does not consider later events which might affect the cost-effectiveness positively. The economic evaluation (Markov model) performed in Sweden in patients $>75$ years of age with a recent ischemic stroke supports the sensitivity of the time horizon on the outcome: after 7 years, handheld ECG screening was cost saving compared to no screening alternative whereas decreasing the analyzed time horizon to 5 years yielded $7900 €$ per QALY gained ${ }^{16}$. However, the mean age of the patient population in the Sweden trial was higher than in the underlying trial FIND-AF RANDOMISED, which interrelates with the prevalence of $\mathrm{AF}^{4}$ and additionally hampers the comparability of results.

\section{Strengths and limitations}

This economic evaluation is the first analysis of healthcare resource use and $\mathrm{HRQ}$ oL in patients with unspecific stroke in Germany, comparing 10 day Holter monitoring with $24 \mathrm{~h}$ ECG monitoring for detection of PAF in the population at risk.

Because of the bottom-up method, the collected cost data display a good estimate for the real healthcare utilization related to stroke in Germany within the first year after the event.

Find-AF $F_{\text {RANDOMISED }}$ generates generalizable results due to the chosen comparator ( $\mathrm{SoC}$ ) and by applying pre-specified inclusion and unrestricted exclusion criteria in urban and rural SUs to include only a relevant patient population. The frequent intervals of measurements reduce the risk of recall bias and ensure reasonable estimates.

The societal perspective provides the possibility to use the analysis by various stakeholders. In addition, using QALYs as outcome enables decision-making bodies to compare results for different health technologies or interventions.

However, there are some limitations. First, the valuation of costs and utilities is based on the German healthcare system and is rather specific to the German setting and its healthcare landscape.

Second, $21.7 \%$ of the patients in the SoC group had a previous ischemic stroke compared to $17 \%$ of the EPM group, which is the reason for the higher healthcare resource use at baseline in the SoC group. Although the difference in mean baseline costs was not statistically significant between the EPM and SoC groups, a regression-based correction method was applied to avoid potential bias. As the difference in baseline utilities was 0.02 , adjustment of utilities was only performed in a sensitivity analysis.

Third, costs might be underestimated. Non-healthcare costs like informal care or travel expenses were not considered, despite the chosen societal perspective. Literature has shown that informal care might account for $6-7 \%$ of health expenditures related to stroke ${ }^{37,38}$. Furthermore, initial hospitalization costs were not considered as the focus was on stroke-related follow-up costs. Moreover, the friction period of 90 days is a conservative estimate but in accordance with national considerations ${ }^{20}$. However, the mean age in this population is above retirement age, thus productivity losses account for only a low percentage of costs compared to healthcare utilization costs. Nevertheless, to reassure robustness of results the HCA was applied in one of the three sensitivity analyses whereas another sensitivity analysis considered only direct healthcare costs.

Fourth, 30\% of patients had to be excluded in the CCA. This approach was deemed necessary to get reliable data. To account for differences in the demographic characteristics, a second analysis was conducted including patients with one missing measurement point. The second analysis covered $80 \%$ of the initial sample and resulted in representative results with similar demographic characteristics between the analyzed and excluded patients.

Fifth, in this study, the follow-up period after randomization was 12 months. Possible implications for arrhythmias in stroke occurrence and related costs that occur beyond this period are not covered. Thus, further studies are required that investigate the cost-effectiveness of prolonged and enhanced Holter ECG monitoring in the long term. In this context, the role of care managers may be considered. Care managers for cardiovascular diseases have proven to achieve better compliances with care recommendations (e.g. adherence to medical therapy) and thus may decrease the risk of hospitalization or the worsening of clinical parameters ${ }^{39}$. Care managers may improve secondary stroke prevention by monitoring health status and ensuring compliance with medical therapy, which may positively affect outcomes and related costs.

Finally, we were not able to analyze whether strokes in certain cerebral vascular territories benefit more or less from monitoring. This is explained by the medium sample size and the fact that most patients only had one initial cerebral imaging (usually computer tomography) but did not receive follow-up imaging to exactly identify the ischemic brain area.

However, all assumptions and approximations necessary were made following a conservative approach.

\section{Conclusion}

The economic evaluation of prolonged and enhanced Holter ECG monitoring compared to SoC yielded nonsignificant results but indicated a moderate probability for being costeffective. Find-AF $F_{\text {RANDOMISED }}$ revealed significant clinical outcomes with regard to the detection rate of $A F$ in ischemic stroke patients and led to fewer strokes, transient ischemic attacks and cases of death ${ }^{19}$. Hence, EPM might be recommended in patients at risk of recurrent stroke as an efficient method to detect PAF in time, enhance secondary prevention and decrease the burden of disease without increasing the costs for society or reducing HRQoL. However, this economic evaluation was performed across a period of only one year; therefore, an evaluation of an extended period should be considered in the future. 


\section{Transparency}

\section{Declaration of funding}

The trial is sponsored by the IFS (Institut für anwendungsorientierte Forschung und klinische Studien) and supported by Boehringer Ingelheim with an unrestricted grant.

\section{Declaration of financial/other relationships}

K.G. has disclosed that he has received personal fees from Bayer, Boehringer Ingelheim, BMS, Daiichi Sankyo and Pfizer. G.F.H. has disclosed that he has participated as local PI in the clinical trials RESPECTESUS and MOnDafis. P.K. has disclosed that he has received honoraria for participation in clinical trials, contributions to advisory boards or oral presentations from: Abbvie, Bayer Vital, Biogen, BMS, Boehringer Ingelheim, Daiichi-Sankyo, Genzyme, Novartis, Pfizer, TEVA and UCB. G.G. has disclosed that he has received remuneration from the University Medicine Göttingen for statistical analysis and work in the steering com-

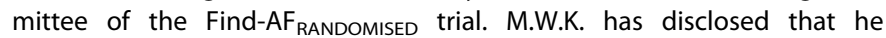
obtained a travel grant from Pfizer. R.W. has disclosed that he has been an investigator or consultant for, or received fees from Bayer, Berlin Chemie, Bristol-Myers-Squibb, Boehringer Ingelheim, Boston Scientific, CVRx, Gilead, Johnson \& Johnson, Medtronic, Novartis, Pfizer, Relypsa, Sanofi and Servier since 2003 outside the submitted work; he received research grants from Boehringer Ingelheim, European Union and Bundesministerium für Bildung und Forschung (BMBF). J.L. has disclosed that he has received honoraria for oral talks of Advisory Boarding from the following companies: Bayer Healthcare, Boehringer Ingelheim, Stryker, Pfizer, Daiichi Sankyo. No potential conflict of interest was reported by the other authors. CMRO peer reviewers on this manuscript have no relevant financial or other relationships to disclose.

\section{Acknowledgements}

None reported.

\section{ORCID}

Silvia Evers (ID http://orcid.org/0000-0003-1026-570X

Mickaël Hiligsmann (D) http://orcid.org/0000-0003-4274-9258

\section{References}

[1] Zhang $Y$, Chapman AM, Plested $M$, et al. The incidence, prevalence, and mortality of stroke in France, Germany, Italy, Spain, the UK, and the US: a literature review. Stroke Res Treat. 2012; 2012:3329668.

[2] Evers SM, Struijs JN, Ament AJ, et al. International comparison of stroke cost studies. Stroke. 2004;35:1209-1215.

[3] Kolominsky-Rabas PL, Heuschmann PU, Marschall D, et al. Lifetime cost of ischemic stroke in Germany: results and national projections from a population-based stroke registry: the Erlangen Stroke Project. Stroke. 2006;37:1179-1183.

[4] Hahne K, Monnig G, Samol A. Atrial fibrillation and silent stroke: links, risks, and challenges. Vasc Health Risk Manag. 2016;12: 65-74.

[5] Weber-Kruger M, Gelbrich G, Stahrenberg R, et al. Finding atrial fibrillation in stroke patients: randomized evaluation of enhanced and prolonged Holter monitoring - Find-AF(RANDOMISED) rationale and design. Am Heart J. 2014;168:438-445 e1.

[6] Kamel H, Smith WS. Detection of atrial fibrillation and secondary stroke prevention using telemetry and ambulatory cardiac monitoring. Curr Atheroscler Rep. 2011;13:338-343.

[7] Jauch EC, Saver JL, Adams HP Jr, et al. Guidelines for the early management of patients with acute ischemic stroke: a guideline for healthcare professionals from the American Heart Association/ American Stroke Association. Stroke. 2013;44:870-947.

[8] Deutsche Gesellschaft für Neurologie (DGN) [Internet]. S1-Leitlinie zur Diagnostik akuter zerebrovaskulärer Erkrankungen [S1 guideline for the diagnosis of acute cerebrovascular diseases]. 2012 [cited 2016 Oct 25]. Available from: https://www.dsg-info.de/ images/stories/DSG/PDF/Leitlinien/LL_21_2012_diagnostik_akuter_ zerebrovaskulaerer_erkrankungen.pdf.

[9] Stahrenberg R, Weber-Kruger M, Seegers J, et al. Enhanced detection of paroxysmal atrial fibrillation by early and prolonged continuous Holter monitoring in patients with cerebral ischemia presenting in sinus rhythm. Stroke. 2010;41:2884-2888.

[10] Kirchhof $P$, Auricchio A, Bax J, et al. Outcome parameters for trials in atrial fibrillation: recommendations from a consensus conference organized by the German Atrial Fibrillation Competence NETwork and the European Heart Rhythm Association. Europace. 2007;9:1006-1023.

[11] Kirchhof P, Benussi S, Kotecha D, et al. 2016 ESC Guidelines for the management of atrial fibrillation developed in collaboration with EACTS. Eur Heart J. 2016;37:2893-2962.

[12] January CT, Wann LS, Alpert JS, et al. 2014 AHA/ACC/HRS guideline for the management of patients with atrial fibrillation: a report of the American College of Cardiology/American Heart Association Task Force on practice guidelines and the Heart Rhythm Society. Circulation. 2014;130:e199-267.

[13] European Heart Rhythm Association, European Association for Cardio-Thoracic Surgery, Camm AJ, et al. Guidelines for the management of atrial fibrillation: the Task Force for the Management of Atrial Fibrillation of the European Society of Cardiology (ESC). Eur Heart J. 2010;31:2369-2429.

[14] Hart RG, Pearce LA, Aguilar MI. Meta-analysis: antithrombotic therapy to prevent stroke in patients who have nonvalvular atrial fibrillation. Ann Intern Med. 2007;146:857-867.

[15] Baturova MA, Lindgren A, Carlson J, et al. Non-permanent atrial fibrillation and oral anticoagulant therapy are related to survival during 10 years after first-ever ischemic stroke. Int J Cardiol. 2017;232:134-139.

[16] Levin LA, Husberg M, Sobocinski PD, et al. A cost-effectiveness analysis of screening for silent atrial fibrillation after ischaemic stroke. Europace. 2015;17:207-214.

[17] Aronsson M, Svennberg E, Rosenqvist M, et al. Cost-effectiveness of mass screening for untreated atrial fibrillation using intermittent ECG recording. Europace. 2015;17:1023-1029.

[18] Mayer F, Stahrenberg R, Groschel K, et al. Cost-effectiveness of 7-day-Holter monitoring alone or in combination with transthoracic echocardiography in patients with cerebral ischemia. Clin Res Cardiol. 2013;102:875-884.

[19] Wachter R, Groschel K, Gelbrich G, et al. Holter-electrocardiogram-monitoring in patients with acute ischaemic stroke (FindAFRANDOMISED): an open-label randomised controlled trial. Lancet Neurol. 2017;16:282-290.

[20] Institut für Qualität und Wirtschaftlichkeit im Gesundheitswesen (IQWiG) [Internet]. Allgmeine Methoden (Entwurf für Version 5.0 vom 07.12.2016) [General methods (draft for version 5.0 of 07.12.2016)]. 2016 [cited 2016 Apr 9]. Available from: https:// www.iqwig.de/download/IQWiG_Methoden_Entwurf-fuer-Version5_final.pdf.

[21] Husereau D, Drummond M, Petrou S, et al. Consolidated Health Economic Evaluation Reporting Standards (CHEERS) statement. Int J Technol Assess Health Care. 2013;29:117-122.

[22] Ramsey SD, Willke RJ, Glick $H$, et al. Cost-effectiveness analysis alongside clinical trials II - an ISPOR Good Research Practices Task Force report. Value Health. 2015;18:161-172.

[23] Brooks R. EuroQol: the current state of play. Health Policy. 1996; 37:53-72.

[24] Manca A, Hawkins N, Sculpher MJ. Estimating mean QALYs in trial-based cost-effectiveness analysis: the importance of controlling for baseline utility. Health Econ. 2005;14:487-496. 
[25] EuroQoL group. How to use EQ-5D 2016 [Internet] [cited 2016 Apr 23]. Available from: http://www.euroqol.org/about-eq-5d/ how-to-use-eq-5d.html

[26] Hunger M, Sabariego C, Stollenwerk B, et al. Validity, reliability and responsiveness of the EQ-5D in German stroke patients undergoing rehabilitation. Qual Life Res. 2012;21:1205-1216.

[27] Greiner W, Claes C, Busschbach JJ, et al. Validating the EQ-5D with time trade off for the German population. Eur J Health Econ. 2005;6:124-130.

[28] Bock JO, Brettschneider C, Seidl $\mathrm{H}$, et al. Calculation of standardised unit costs from a societal perspective for health economic evaluation. Gesundheitswesen. 2015;77:53-61.

[29] Schwabe U, Paffrath D, Arzneiverordnungs-Report 2015. Aktuelle Daten, Kosten, Trends und Kommentare [Drug Prescription Report 2015. Current Data, Costs, Trends and Comments]. Berlin: Springer Berlin Heidelberg; 2015.

[30] Bundesministerium für Gesundheit (BMG). Pflegeleistungen ab Januar 2015 [Nursing services from January 2015] [Internet]. 2015 [cited 2016 Aug 9]. Available from: http://www.bmg.bund.de/fileadmin/dateien/Downloads/P/Pflegestaerkungsgesetze/Tabellen_ Plegeleistungen_BRat_071114.pdf

[31] Statistisches Bundesamt [Internet]. Volkswirtschaftliche Gesamtberechnung. Fachserie 18, Reihe 1.4 [Economic total calculation. Subject series 18, series 1.4]. 2015 [cited 2016 Apr 23]. Available from: https://www.destatis.de/DE/Themen/Wirtschaft/ Volkswirtschaftliche-Gesamtrechnungen-Inlandsprodukt/Publikationen/ Downloads-Inlandsprodukt/inlandsprodukt-vorlaeufig-xlsx-2180140.xlsx ? blob=publicationFile.
[32] Bundesagentur für Arbeit. Statistik. Gemeldete Arbeitsstellen [Statistics. Registered jobs] [Internet]. 2016 [cited 2016 Apr 25]. Available from: https://statistik.arbeitsagentur.de/Navigation/Statistik/ Statistik-nach-Themen/Arbeitslose-und-gemeldetes-Stellenangebot/ Gemeldete-Stellen/Gemeldete-Arbeitsstellen-Nav.html

[33] Drummond M, McGuire A. Economic Evaluation in Health Care. Merging Theory with Practice. New York: Oxford University Press; 2001.

[34] Koopmanschap MA, Rutten FF, van Ineveld BM, et al. The friction cost method for measuring indirect costs of disease. J Health Econ. 1995;14:171-189.

[35] van Asselt $A D$, van Mastrigt $G A$, Dirksen $C D$, et al. How to deal with cost differences at baseline. Pharmacoeconomics. 2009;27: 519-528.

[36] Drummond M, Sculpher MJ, Torrance GW, et al. Methods for the Economic Evaluation of Health Care Programmes. 3rd ed. New York: Oxford University Press; 2005.

[37] van Eeden $M$, van Heugten $C$, van Mastrigt GA, et al. The burden of stroke in the Netherlands: estimating quality of life and costs for 1 year poststroke. BMJ Open. 2015;5:e008220.

[38] Persson J, Ferraz-Nunes J, Karlberg I. Economic burden of stroke in a large county in Sweden. BMC Health Serv Res. 2012;12:341.

[39] Ciccone MM, Aquilino A, Cortese F, et al. Feasibility and effectiveness of a disease and care management model in the primary health care system for patients with heart failure and diabetes (Project Leonardo). Vasc Health Risk Manag. 2010;6: 297-305. 